\title{
Título da página electrónica: ProVentium
} Consortium

URL: http://www.proventionconsortium.org/

\section{Susana Freiria}

\section{OpenEdition}

\section{Journals}

Edição electrónica

URL: http://journals.openedition.org/rccs/1415

DOI: $10.4000 /$ rccs. 1415

ISSN: 2182-7435

\section{Editora}

Centro de Estudos Sociais da Universidade de Coimbra

Edição impressa

Data de publição: 1 junho 2011

Paginação: 208

ISSN: 0254-1106

\section{Refêrencia eletrónica}

Susana Freiria, «Título da página electrónica: ProVentium Consortium », Revista Crítica de Ciências Sociais [Online], 93 | 2011, posto online no dia 01 dezembro 2012, consultado o 22 setembro 2020. URL : http://journals.openedition.org/rccs/1415; DOI : https://doi.org/10.4000/rccs.1415 


\section{Espaço Virtual}

\section{Título da página electrónica: United Nations University - Institute for Environment and Human Security URL: http://www.ehs.unu.edu}

A Universidade das Nações Unidas procura estabelecer pontes entre o mundo académico e o sistema das Nações Unidas. O Institute for Environment and Human Security (UNU-EHS, na sigla original), em específico, tem por objectivo o desenvolvimento de soluções sustentáveis para os problemas actuais e futuros da humanidade, incluindo-se neste vasto campo de actuação o estudo do risco e da vulnerabilidade. O UNU-EHS assume um papel de liderança nas acções de investigação e de capacitação que desenvolve no âmbito dos seus projectos e pretende contribuir para um conhecimento mais aprofundado e para uma melhor compreensão dos processos em diversos campos, como sejam a pobreza, a governação e as emergências humanitárias.

As 4 secções académicas que o compõem são: Environmental Migration, Social Vulnerability \& Adaptation Section;
Vulnerability Assessment, Risk Management E Adaptive Planning Section; Environmental Vulnerability \& Energy Security Section e Enhancing Graduate Educational Capacities for Human Security Section.

A UNU-EHS estabelece também relações com grupos de peritos e redes de investigação, como por exemplo a Social Vulnerability Network, de que é coordenadora desde 2006, e a Munich Re Foundation Chair on Social Vulnerability, que actua na investigação e disseminação do conhecimento sobre políticas de vulnerabilidade social. Neste âmbito, têm sido realizadas formações como os cursos de Verão anuais, que contam com a participação de investigadores consagrados, nomeadamente a Professora Susan Cutter, que esteve em 2010 em Portugal, no âmbito de uma conferência organizada pelo Centro de Estudos Sociais (CES).

\section{Título da página electrónica: International Risk Governance Council URL: http://www.irgc.org}

\section{O International Risk Governance Council} (IRGC) é uma organização independente cuja missão é ajudar a compreender e a gerir riscos globais emergentes que têm impacto na segurança, saúde humana, ambiente, economia e na sociedade. O IRGC focaliza a sua acção no desenvolvimento de conceitos e estratégias de governação do risco, sendo esta uma área crucial perante a necessidade de tomar decisões relacionadas com o risco e de conseguir uma maximização da confiança das comunidades nos processos e nas estruturas que causam e geram os processos de perigo.

A página do IRGC inclui um vasto e diverso conjunto de publicações, atinentes à problemática da governação do risco em contexto de simultânea complexidade, incerteza e ambiguidade, caracterizadores da maioria dos riscos emergentes e sistémicos com que se deparam as sociedades actuais 
- de que o sismo de 11 de Março de 2011 no Japão é possivelmente o exemplo mais actual e paradigmático.

O primado actual de investigação do IRGC direcciona-se para o tipo de riscos cujos processos de governação se encontram ainda pouco consolidados, como sejam os riscos associados às alterações climáticas, aos recursos energéticos e à utilização de nanotecnologia.

\section{Pedro Pinto dos Santos}

\section{Título da página electrónica: ProVentium Consortium URL: http://www.proventionconsortium.org/}

O Consórcio ProVentium, criado em 2000, resulta de uma iniciativa que reúne governos, organizações do sector privado, da sociedade civil e de âmbito académico. $\mathrm{O}$ facto de reunir instituições provenientes de sectores tão diversos contribui para criar uma plataforma de diálogo que incorpora diferentes pontos de vista. Este consórcio tem como objectivo aumentar a segurança das comunidades mais vulneráveis e reduzir os impactos dos desastres. A página principal encontra-se dividida em três secções: o papel desempenhado pelo Consórcio na gestão do risco, as actividades desenvolvidas pela instituição e uma terceira secção dedicada à disponibilização de manuais.

Neste sítio electrónico é possível encontrar um vasto manancial de informação com uma perspectiva inovadora e manuais no âmbito da gestão do risco, em vertentes como a análise de custo-benefício, estratégias de adaptação às mudanças climáticas e casos de estudo de recuperação de desastres. Os manuais disponibilizados encontram-se muito bem estruturados, de fácil leitura, constituindo valiosas ferramentas de trabalho. Para além dos manuais dirigidos ao público académico e aos operacionais, são também disponibilizados vídeos, alguns dos quais dirigidos ao público infantil. Pretende-se que todos saibam como prevenir, mitigar e recuperar de um evento potencialmente danoso.

A abordagem desenvolvida por este Consórcio é bastante inovadora. Pode-se apontar uma metodologia denominada Community Risk Assessment (CRA), em que a participação pública desempenha um papel fundamental no diagnóstico da situação, na definição e implementação de estratégias de prevenção e mitigação. Na página electrónica em análise explica-se passo a passo como se pode aplicar esta metodologia. A CRA procura identificar os grupos mais vulneráveis e explorar as capacidades locais que podem ser usadas no sentido de aumentar a resiliência dos membros da comunidade. É dada bastante importância a que as estratégias definidas sejam efectivamente implementadas e que essa implementação seja acompanhada por um processo de avaliação.

\section{Título da página electrónica: EM-DAT, The International Disaster Database - Centre for Research on the Epidemiology of Disaster (CRED) URL: http://www.emdat.be/}

A EM-DAT consiste numa base de dados com mais de 18000 grandes desastres ocorridos em todo o mundo desde 1900.
Um dado fenómeno é considerado um desastre quando se verifica pelo menos uma das seguintes situações: 10 ou mais 
pessoas são dadas como vítimas mortais; 100 ou mais pessoas são registadas como afectadas; é emitida uma declaração de estado de emergência; é feito um pedido de ajuda internacional.

A base é mantida pelo Centro de Pesquisa em Epidemiologia de Desastres, na Escola de Saúde Pública da Universidade Católica de Louvain, localizada em Bruxelas, na Bélgica. O referido Centro conta com a colaboração de agências não-governamentais, agências noticiosas e de seguros para manter a base actualizada. Além disso, são regularmente organizados reuniões, workshops e conferências com vários stakeholders, no sentido de melhorar a metodologia de recolha e tratamento de dados de desastres. A EM-DAT constitui a fonte oficial de dados estatísticos a nível de desastres da UNISDR (United Nations - International Strategy for Disaster Reduction). Todos os anos o CRED e a UNISDR organizam uma conferência de imprensa, a fim de revelar os números oficiais relacionados com os desastres do ano anterior e os respectivos impactos.

Os dados podem ser consultados de diversas formas, existindo inclusive a possibilidade de o utilizador construir a sua própria base a partir de parâmetros como a localização, período de tempo, tipo de desastre (natural, tecnológico, etc.). Além de fornecer um vasto conjunto de dados numéricos por país e região mundial, também disponibiliza um conjunto de mapas através dos quais é possível identificar as áreas onde, por exemplo, os desastres naturais provocaram prejuízos económicos mais elevados.

Para além da base, encontra-se disponível na página a metodologia e critérios que a suportam (como um glossário e a forma como a informação de cada desastre é tratada), assim como os trabalhos desenvolvidos pelos investigadores do CRED. A página, em constante actualização, encontra-se bem estruturada, sendo fácil e rápido o acesso de qualquer utilizador a um vasto conjunto de materiais, de grande utilidade para todo o tipo de público, desde o académico até ao leigo interessado pelas matérias relacionadas com a gestão do risco. Nesta página é possível encontrar um dos acervos mais relevantes para quem se interessa por e trabalha na gestão do risco.

\section{Susana Freiria}

